\title{
Methotrexate: a useful alternative in Crohn's disease?
}

Feagan BG, Fedorak RN, Irvine EJ, et al, for the North American Crohn's study group. A comparison of methotrexate with placebo for the maintenance of remission in Crohn's disease. $N$ Engl $\mathcal{f}$ Med 2000;342:1627-32.

\section{Question}

In patients with Crohn's disease who are in remission after receiving methotrexate, does continuing methotrexate prolong remission?

\section{Design}

Randomised double blind trial of 40 weeks of continued treatment or withdrawal.

\section{Setting}

Seven university medical centres in North America.

\section{Patients}

Seventy six patients with previous chronically active Crohn's disease and no risk factors for methotrexate toxicity who had successfully completed a course of methotrexate injections ( $25 \mathrm{mg}$ intramuscularly every week for 16 weeks) and at recruitment had a Crohn's disease activity index of 150 or less and were not taking prednisone.

\section{Intervention}

Patients were allocated to either continuing methotrexate at a dose of $15 \mathrm{mg}$ intramuscularly every week for 40 weeks or placebo injections.

\section{Outcome measures}

The primary outcome was the occurrence of a Crohn's disease relapse, defined as an increase in CDAI of at least 100 or the need for prednisone or an antimetabolite, or both, for recurrent symptoms. The need for prednisone was a secondary outcome.

\section{Results}

Of 125 patients assessed, 38 patients refused consent. Of 76 eligible patients, 23 were enrolled from the previous randomised trial and 53 from an open label study. At 40 weeks, $65 \%$ (26/40) of methotrexate treated patients remained in remission compared with $39 \%(14 / 36)$ of those receiving placebo injections $(p=0.04$, absolute reduction in risk of relapse $26 \%$, $95 \%$ confidence intervals $4-48 \%$ ). Median duration of remission on placebo was 22 weeks compared with more than 40 weeks for those receiving methotrexate. Twenty eight per cent $(11 / 40)$ of the methotrexate group required prednisone compared with 58\% $(21 / 36)$ of those in the placebo group $(p=0.01)$.

Nausea and vomiting occurred more frequently in the methotrexate group ( $40 \% v 25 \%)$ but other side effects were equally common in the two groups. No patient had leucopenia that was severe enough to require withholding methotrexate and none of the patients in the methotrexate group suffered a severe adverse event.

\section{Conclusion}

Methotrexate given for 40 weeks at a dose of $15 \mathrm{mg}$ intramuscularly every week maintained remission, was well tolerated, and appeared to be safe.

\section{Comment}

The search goes on for safe and effective long term treatments that will modify the course of aggressive Crohn's disease and reduce the need for frequent surgery or long term corticosteroids. Azathioprine and 6-mercaptopurine remain the most widely used immunomodulators but there is a need for alternatives, particularly for the $10 \%$ of patients who cannot tolerate these drugs. Methotrexate has been used in Crohn's disease for many years ${ }^{1-3}$ and a controlled trial showed benefit in active corticosteroid dependent disease ${ }^{4}$ yet it is still not widely used. Likely reasons include concerns about toxicity (particularly liver fibrosis, hypersensitivity pneumonitis, and teratogenicity), the need for parenteral administration, and lack of evidence of long term benefit.

The recent publication of Feagan and colleagues ${ }^{5}$ provides important information on the long term role of methotrexate. While not obvious from the paper's title, this was in fact a placebo controlled withdrawal study in 76 patients who had achieved remission (judged by Crohn's disease activity index) after methotrexate $25 \mathrm{mg}$ intramuscularly weekly for 4-6 months. Forty patients then received methotrexate $15 \mathrm{mg}$ intramuscularly every week, and the remainder received placebo injections for 40 weeks. Significantly more remained in remission on methotrexate $(65 \%)$ than those on no treatment $(39 \%)$. This benefit of maintenance treatment was of course in a highly selected group of patients who had already demonstrated responsiveness to methotrexate and who also tolerated the drug at a higher dose (17\% previously withdrawn from the $25 \mathrm{mg}$ study $^{4}$ ). Perhaps unsurprisingly, the maintenance dose was well tolerated, with only one withdrawal for nausea and none for leucopenia or abnormal liver function.

With this recent addition to the controlled evidence, it is appropriate to summarise our current knowledge of methotrexate in Crohn's disease. Liver toxicity is not a problem for cumulative doses up to $5 \mathrm{~g},{ }^{6}{ }^{7}$ and regular liver biopsy is not needed. Methotrexate is given weekly, as daily dosage increases the risk of toxicity. Folic acid $1 \mathrm{mg}$ daily reduces haematological toxicity. Side effects are common, particularly nausea and headache, but are usually mild and dose related, requiring drug withdrawal in only $10 \% .^{3}$ Cough or dyspnoea should raise suspicion of pneumonitis but this is uncommon (1-2\%) and usually settles with corticosteroids if methotrexate is withdrawn promptly.

Oral absorption is not reduced in small bowel Crohn's disease $\mathrm{e}^{8}$ but absorption is highly variable and is also dose dependent, with bioavailability decreasing by a mean $13.5 \%$ when the dose is increased from $7.5 \mathrm{mg}$ to $15-20$ mg weekly. ${ }^{9}$ There is anecdotal evidence of a dose threshold for response but no evidence that doses higher than $25 \mathrm{mg}$ are beneficial. Responders should switch to oral dosing, and the lowest effective dose should be continued; if patients relapse on low doses, it is logical to increase the dose or switch from oral to intramuscular treatment.

There is now strong evidence for a role for methotrexate in Crohn's disease but many questions remain. Does it act more rapidly than the purine analogues? (The only head to head study does not show this. ${ }^{10}$ ) Is intramuscular injection always needed initially? How long should treatment be continued in responders? The theoretical concerns about 
malignancy remain for all long term immunosuppression. Although overall tolerability is comparable with the purine analogues, methotrexate will remain my second choice, particularly in women, because of teratogenicity. It is however a useful alternative, and with careful monitoring and dose adjustment is worthy of more widespread use.

University Hospital of Wales,

A B HAWTHORNE

Heath Park, Cardiff CF14 4XW, UK

Barney.Hawthorne@UHW-TR.wales.nhs.uk

1 Kozarek RA, Patterson DJ, Gelfand MD, et al. Methotrexate induces clinical and histologic remission in patients with refractory inflammatory bowel disease. Ann Intern Med 1989;110:353-6.

2 Baron TH, Truss CD, Elson CO. Low dose oral methotrexate in refractory inflammatory bowel disease. Dig Dis Sci 1993;38:1851-6.
3 Lemann M, Zenjari T, Bouhnik Y, et al. Methotrexate in Crohn's disease: long-term efficacy and toxicity. Am f Gastroenterol 2000;95:1730-4.

4 Feagan BG, Rochon J, Fedorak RN, et al. Methotrexate for the treatment of Crohn's disease. N Engl f Med 1995;332:292-7.

5 Feagan BG, Fedorak RN, Irvine EJ, et al. A comparison of methotrexate with placebo for the maintenance of remission in Crohn's disease. $N$ Engl F Med 2000;342:1627-32.

6 Te HS, Schiano TD, Kuan SF, et al. Hepatic effects of long-term methotrexate use in the treatment of inflammatory bowel disease. Am $\mathcal{F}$ Gastroenterol 2000;95:3150-6.

7 Tang H, Neuberger J. Review article: methotrexate in gastroenterologydangerous villain or simply misunderstood? Aliment Pharmacol Ther 1996 10:851-8.

8 Moshkowitz M, Oren R, Tishler M, et al. The absorption of low-dose methotrexate in patients with inflammatory bowel disease. Aliment Pharmacol Ther 1997;11:569-73.

9 Hamilton RA, Kremer JM. Why intramuscular methotrexate may be more efficacious than oral dosing in patients with rheumatoid arthritis. $\mathrm{Br} \mathcal{F}$ Rheumatol 1997;36:86-90.

10 Ardizzone S, Bollani S, Manzionna BG, et al. Controlled trial comparing intravenous methotrexate and oral azathioprine for chronic active Crohn's disease: preliminary report. Gastroenterology 1999;116:A662 